\title{
New Battery Balancing Circuit using Magnetic Flux Sharing
}

\author{
Sung-Geun Song ${ }^{*}$, Seong-Mi Park ${ }^{\dagger}$, and Sung-Jun Park ${ }^{* *}$ \\ "Korea Electronics Technology Institute, Gwangju, Korea \\ 'Dept. of Mechatronics Eng., Korea Lift College, Geochang, Korea \\ ${ }^{* *}$ Dept. of Electrical Eng., Chonnam National University, Gwangju, Korea
}

\begin{abstract}
To increase the capacity of secondary cells, an appropriate serial composition of the battery modules is essential. The unbalance that may occur due to the series connection in such a serial composition is the main cause for declines in the efficiency and performance of batteries. Various studies have been conducted on the use of a passive or active topology to eliminate the unbalance from the series circuit of battery modules. Most topologies consist of a complex structure in which the Battery Management System (BMS) detects the voltage of each module and establishes the voltage balancing in the independent electrical power converters installed on each module by comparing the module voltage. This study proposes a new magnetic flux sharing type DC/DC converter topology in order to remove voltage unbalances from batteries. The proposed topology is characterized by a design in which all of the DC/DC convertor outputs connected to the modules converge into a single transformer. In this structure, by taking a form in which all of the battery balancing type converters share magnetic flux through a single harmonic wave transformer, all of the converter voltages automatically converge to the same voltage. This paper attempts to analyze the dynamic properties of the proposed circuit by using a Programmable Synthesizer Interface Module (PSIM), which is useful for power electronics analysis, while also attempting to demonstrate the validity of the proposed circuit through experimental results.
\end{abstract}

Key words: Battery balancing, Battery management system, DC/DC converter

\section{INTRODUCTION}

With the recent emergence of smart grids, interest in the use of a secondary battery, as energy storage device is increasing. Today, secondary batteries are being applied in industries in various forms. In particular, many studies on the use of batteries are being conducted in response to the irregular output produced by most of the new regeneration energies and the consequent increase in battery capacities [1]-[3]. To increase the size of batteries, the serial composition of battery modules is essential, and any voltage unbalance that may occur during charging and discharging due to the series connection of battery modules is the main cause for the efficiency degradation of batteries [8], [9].

Therefore, this study proposes a new magnetic flux sharing type DC/DC converter topology in order to remove voltage

Manuscript received Feb. 20, 2013; revised Nov. 12, 2013

Recommended for publication by Associate Editor Woo-Jin Choi.

${ }^{\dagger}$ Corresponding Author: seongmi@klc.ac.kr

Tel: +82-55-949-2251, Fax: +82-55-949-2268, Korea Lift College

*Korea Electronics Technology Institute, Korea

${ }^{* *}$ Dept. of Electrical Eng., Chonnam National University, Korea unbalance from batteries. The proposed topology is characterized by a design in which all of the DC/DC convertor outputs connected to batteries in series converge into a single insulating transformer with a 1:1 turns ratio. In this structure, by taking a form in which all of the battery balancing type converters share magnetic flux through a single harmonic wave transformer, all of the converter voltages automatically converge to the same voltage. In particular, this structure can trace the voltage of several series-connected batteries with only one voltage detection. Therefore it can remove a number of the voltage sensors for BMS control and there is an advantage to the primary power to convert all of the modules [4]-[7].

This paper attempts to analyze the dynamic properties of the proposed circuit using a PSIM, which is useful for power electronics analysis, while attempting to demonstrate the validity of the proposed circuit through experimental results.

\section{Voltage Balancing Circuit}

\section{A. General Properties of Chargers}

Fig. 1 shows the curve of ordinary battery discharge 


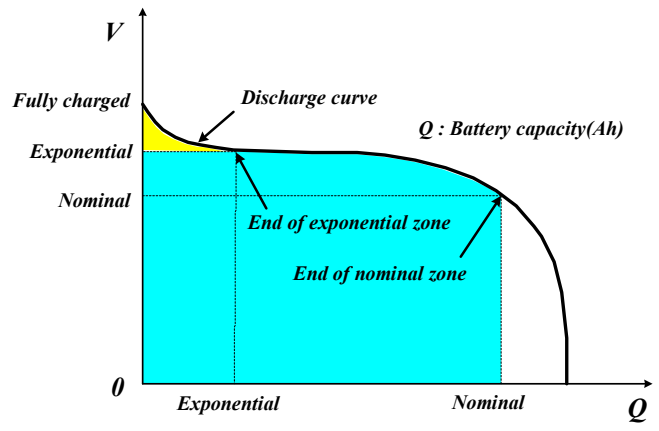

Fig. 1. Battery discharge curve.

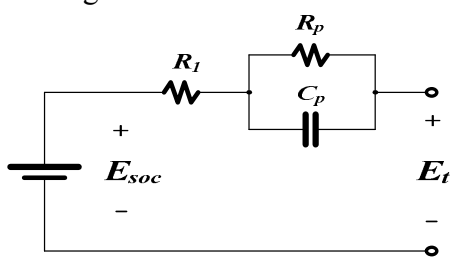

Fig. 2. Battery equivalent circuit.

properties. In discharging at a regular current by connecting a load to a fully charged battery, the battery terminal voltage declines rapidly at an early phase, as shown in the area in the curve called the "Exponential Zone".

The battery terminal voltage then declines slowly yet progressively, as can be seen in the area called the "Nominal Zone". This is the area in which the battery actually operates. If the battery loses its residual capacity, the terminal voltage declines sharply. As the discharge progresses further and reaches below the final discharge voltage (cut-off voltage), the battery's properties weaken, and its life decreases.

Charging a battery usually involves the following steps:

In Step 1, Constant Current charging (CC), the battery's voltage increases. In this process, the battery charges up to about $70 \%$. In Step 2, Constant Voltage charging (CV), the battery is saturated and the charging current slowly decreases. This is the general process of charging in most batteries. The voltage then reaches the battery's limit and the current declines to $3 \%$ of the rated current or maintains its level. Step 3 involves a float charge to compensate for self-discharge.

The equivalent circuit of a battery can be briefly described as the electromotive force $\mathrm{E}(\mathrm{S})$ and series impedance $\mathrm{Z}(\mathrm{S})$ participating in the charging/discharging of the battery, while the actual modeling of the battery is known as the Randles circuit, as shown in Fig. 2. The model expresses the phenomena in the electrode and the solution interface as $\mathrm{R}$ and $\mathrm{C}$, respectively. The equivalent circuit's parameters can be found through a test in which the step function's current is discharged and each parameter is found through changes in the voltage. The open circuit voltage (E) and State of Charge (SOC) are in a linear relationship with each other. In an early phase of discharge, by the capacitance $\mathrm{Cp}$ component, the capacitance driver becomes a short circuit, operating with resistance R1 only, and the capacitance is open in a normal state. As a result, it operates with the sum of R1 and Rp while

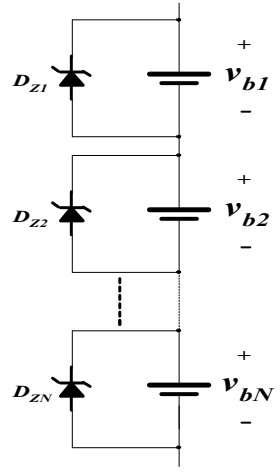

(a) Zener diodes.

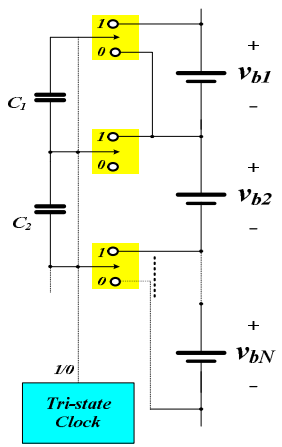

(c) Switched capacitor.

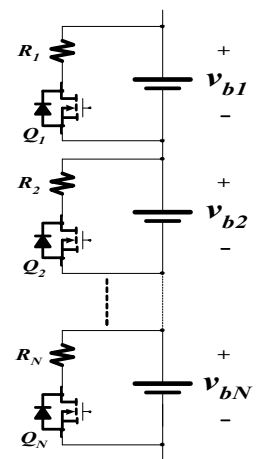

(b) Bypass with resister.

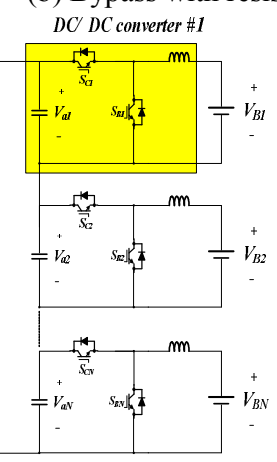

(d) $\mathrm{DC} / \mathrm{DC}$ converter.
Fig. 3. Convention balancing circuits.

$\mathrm{Cp}$ can be calculated from a time constant. However, because the electromotive force and series impedance component contain temperature properties it is difficult to find them immediately. In the position of a charger, the battery's resistance serves to damp, and the size of this value greatly affects the charger's stability.

\section{B. Existing Voltage Balancing Circuit}

When several batteries are connected in series, voltage differences between cells occur due to the very small capacity difference between the batteries. The overcharging of cells caused by this voltage unbalancing expedites the phenomena of a rapid decline in capacity and aging, which result in reduced actual capacity. Various voltage balancing circuits can be used to solve the problems caused by voltage unbalancing. Fig. 3 shows the representative voltage balancing circuits currently used. Fig. 3 (a) is a voltage balancing circuit using a zener diode[1], which is a simple structure using a method that limits the cell's overcharge caused by the zener diode. However, if the cell overcharges and the zener diode conducts, the entire charging current flows on the zener diode. As a result, the power loss generated from the zener diode is significant, which is mainly applied to a small capacity voltage balancing circuit. Fig. 3 (b) shows a discharging method using resistance and a switch emitting display for discharging, where the switch is on through the resistance when the cell is overcharging. This 


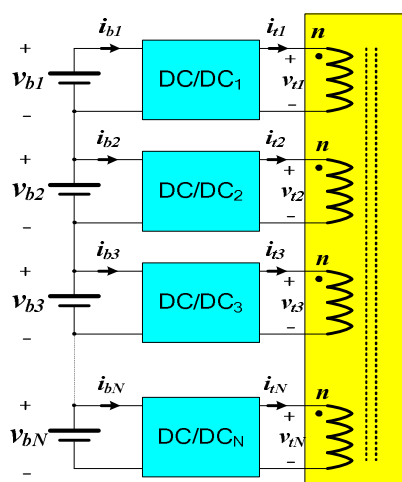

Fig. 4. The proposed voltage balancing structure.

method detects the modules' voltage and switches on and off depending on the reference voltage. Therefore, it does not consume power without over discharging, but has the disadvantage of generating a power loss as it discharge through the resistance when overcharging. Fig. 3 (c) shows a method of delivering a charge to the next cell by parallel composition in each cell using capacitors and switches. In this method, the switch connected to the $\mathrm{N}-1$ capacitors is synchronized. When the switch is on, the condenser is connected to an upper module, and when it is off, it is connected to a lower module. Therefore, it plays a balancing role between the two modules. The disadvantage of this approach is that it takes a longer time to reach voltage stability. Fig. 3(d) shows a method of directly controlling the upper battery's module voltage by connecting a DC/DC converter to the module in parallel. This method requires a switching method to maintain high-performance. The disadvantage of this active voltage balancing, as shown in Figs. 3 (c) and 3(d), is that the delivery loss is significantly increased as the energy at the top layer is conveyed to the energy at the bottom layer through all of the electrical power converters when the bottom layer is undercharging and the top layer is overcharging.

Thus, a study on these balancing circuit regardless of overcharging and undercharging positions is necessary.

\section{The Proposed Voltage Balancing Circuit}

Fig. 4 shows the new structure of the voltage balancing proposed in this study.

The proposed topology, as shown in the figure, is a structure in which $\mathrm{N}$ DC/DC converter(s) are connected with $\mathrm{N}$ battery(ies) series connecting to a harmonic wave transformer with $\mathrm{N}$ coil(s) as sources. The various DC/DC converters expressed in the figure can be constructed such as a half bridge converter, a full bridge converter, a 2 switch forward converter, a fly-back converter, etc. In the N DC/DC converter structure using a high frequency transformer, all of the balancing type converters share $\mathrm{N}$ magnetic flux(es) through one harmonic wave transformer. By applying a number of exciting voltages to the transformer terminal voltage by synchronized signals, the converters converge to the voltage at which all of the

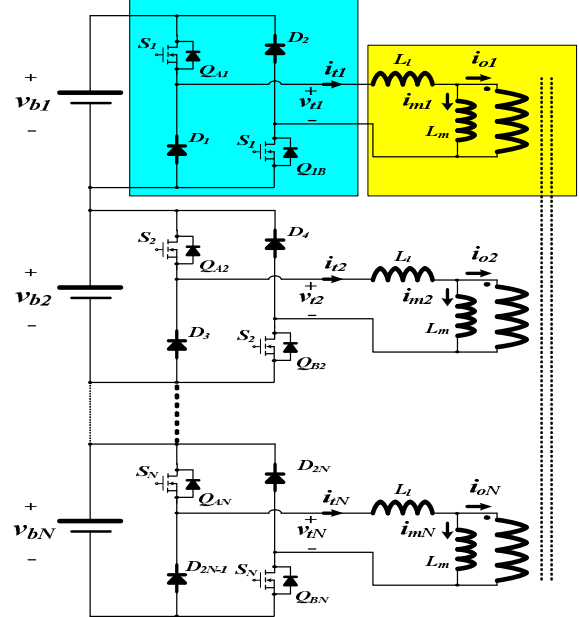

Fig. 5. Proposed voltage balancing circuit.

converters' voltages are automatically equalized.

This is a topology circuit diagram for the case in which two switch forward converters are used in the voltage balancing structure proposed in Fig. 5 and Fig. 4. In the figure, the transformer is expressed as an equivalent circuit constructed with a leakage inductor and an exciter inductor in an ideal 1:1 transformer. In this case, for the design of the convertors, the leakage inductor should be minimized in size to reduce the voltage balancing to a minimum. The equivalent voltage balancing circuit shown in Fig. 5 is shown in Fig. 6 with an on/off switch.

1) On-mode Interpretation: In this converter, the duty rate of the converter was limited to below 0.5 to operate in the current discontinuous mode. Fig. 6(a) shows the equivalent circuit when switched on, and the instantaneous voltage equation is defined as the following formula:

$$
\begin{aligned}
& v_{b 1}=L_{l} \frac{d}{d t} i_{1}+L_{m} \frac{d}{d t} \sum_{k=1}^{N} i_{k} \\
& v_{b 2}=L_{l} \frac{d}{d t} i_{2}+L_{m} \frac{d}{d t} \sum_{k=1}^{N} i_{k} \\
& v_{b N}=L_{l} \frac{d}{d t} i_{N}+L_{m} \frac{d}{d t} \sum_{k=1}^{N} i_{k}
\end{aligned}
$$

The Laplace transform of equation (1) is given by equation (2).

$$
\begin{aligned}
& V_{b 1}(s)=s L_{l} I_{1}(s)+s L_{m} \sum_{k=1}^{N} I_{k}(s) \\
& V_{b 2}(s)=s L_{l} I_{2}(s)+s L_{m} \sum_{k=1}^{N} I_{k}(s) \\
& V_{b N}(s)=s L_{l} I_{2}(s)+s L_{m} \sum_{k=1}^{N} I_{k}(s)
\end{aligned}
$$

To save each of the currents in equation (2), the entire expression [2] is given in equation (3). 


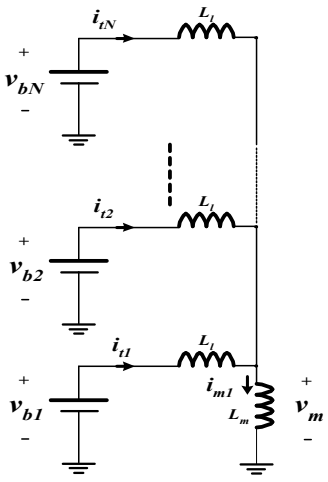

(a) On-mode

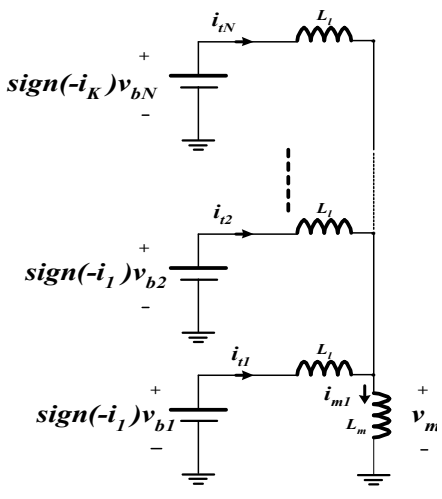

(b) Off-mode.
Fig. 6. Equivalent circuit with the on/off switch.

$$
\sum_{k=1}^{N} V_{b k}(s)=\left(s L_{l}+N s L_{m}\right) \sum_{k=1}^{N} I_{k}(s)
$$

From equations (3) and (2), the currents of each converter are as follows:

$$
\begin{aligned}
& I_{1}(s)=\left[\frac{1}{L_{l}} V_{b 1}(s)-\frac{L_{m}}{L_{l}\left(L_{l}+L_{m}\right)} \sum_{k=1}^{N} V_{b k}(s)\right] \frac{1}{s} \\
& I_{2}(s)=\left[\frac{1}{L_{l}} V_{b 2}(s)-\frac{L_{m}}{L_{l}\left(L_{l}+L_{m}\right)} \sum_{k=1}^{N} V_{b k}(s)\right] \frac{1}{s} \\
& I_{N}(s)=\left[\frac{1}{L_{l}} V_{b N}(s)-\frac{L_{m}}{L_{l}\left(L_{l}+L_{m}\right)} \sum_{k=1}^{N} V_{b k}(s)\right] \frac{1}{s}
\end{aligned}
$$

A time-domain representation of the area of the Laplace equation (4) is given below in equation (5).

$$
\begin{aligned}
& i_{1}(t)=\left(\frac{1}{L_{l}} V_{b 1}-\frac{L_{m}}{L_{l}\left(L_{l}+L_{m}\right)} \sum_{k=1}^{N} V_{b k}\right) t \\
& i_{2}(t)=\left(\frac{1}{L_{l}} V_{b 2}-\frac{L_{m}}{L_{l}\left(L_{l}+L_{m}\right)} \sum_{k=1}^{N} V_{b k}\right) t \\
& i_{N}(t)=\left(\frac{1}{L_{l}} V_{b N}-\frac{L_{m}}{L_{l}\left(L_{l}+L_{m}\right)} \sum_{k=1}^{N} V_{b k}\right) t
\end{aligned}
$$

2) Off-mode Interpretation: The equivalent circuit in gate off is shown in Fig. 6(b). As can be seen in the figure, the polarity of the voltage applied to the transformer coil is determined by the direction of the current, and the current solution is applied to the On-mode interpretation in the same way.

\section{Simulation AND Test Results}

\section{A. Simulation Results}

To verify the validity of the proposed topology, three groups of 2 switch forward converter circuits were constructed for three batteries, as shown in Fig. 7.

In the simulation circuit diagram, to remove the inconvenience of the test due to the length of the voltage balancing time constant if an actual battery is used, the battery was made equivalent to the condenser $(4700 \mathrm{uF})$.
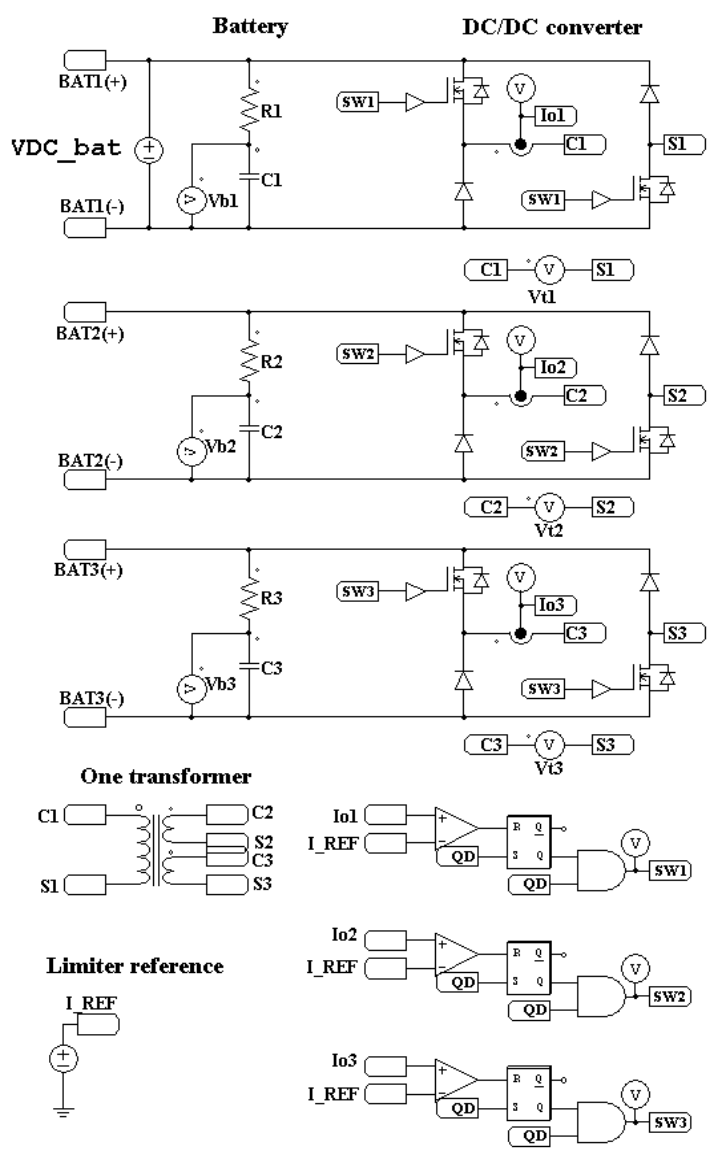

Fig. 7. Voltage stabilization Simulation circuit diagram.

The three DC/DC converters were constructed by using one transformer, and the converter output current was detected if the current was limited by the current limit circuit when it exceeded the set current. The switching frequency realizes Soft Start via a bass passage filter with a cut-up frequency of $5[\mathrm{~Hz}]$ at a 0.4 duty cycle. It sends gate signals synchronized to individual convertors with a switching frequency of $20 \mathrm{k}[\mathrm{Hz}]$.

Fig. 8 shows the results of a simulation to find the characteristics of voltage balancing in the same module. It also depicts the current of the convertors which is composed of three condenser voltages and the same transformer. The initial voltages of the battery equalized condensers $\mathrm{C} 1, \mathrm{C} 2$, and $\mathrm{C} 3$ are marked as $0[\mathrm{~V}], 4[\mathrm{~V}]$, and $12.5[\mathrm{~V}]$, respectively. The energy of condenser $\mathrm{C} 3$ is sent to condensers $\mathrm{C} 2$ and $\mathrm{C} 1$, while the voltage of $\mathrm{C} 3$ decreases, and voltages of $\mathrm{C} 2$ and $\mathrm{C} 1$ increase, making the voltages of the three condensers identical. In a battery circuit equivalent to the condenser, if the series resistance component and the power conversion loss are ignored, the final balancing voltage is given as follows:

$$
v_{b}=\sqrt{\frac{v_{b 1}^{2}+v_{b 2}^{2}+v_{b 3}^{2}}{3}}
$$

Under the conditions of this simulation, the voltages of the three condensers are equalized approximately $45 \mathrm{~ms}$ later and 

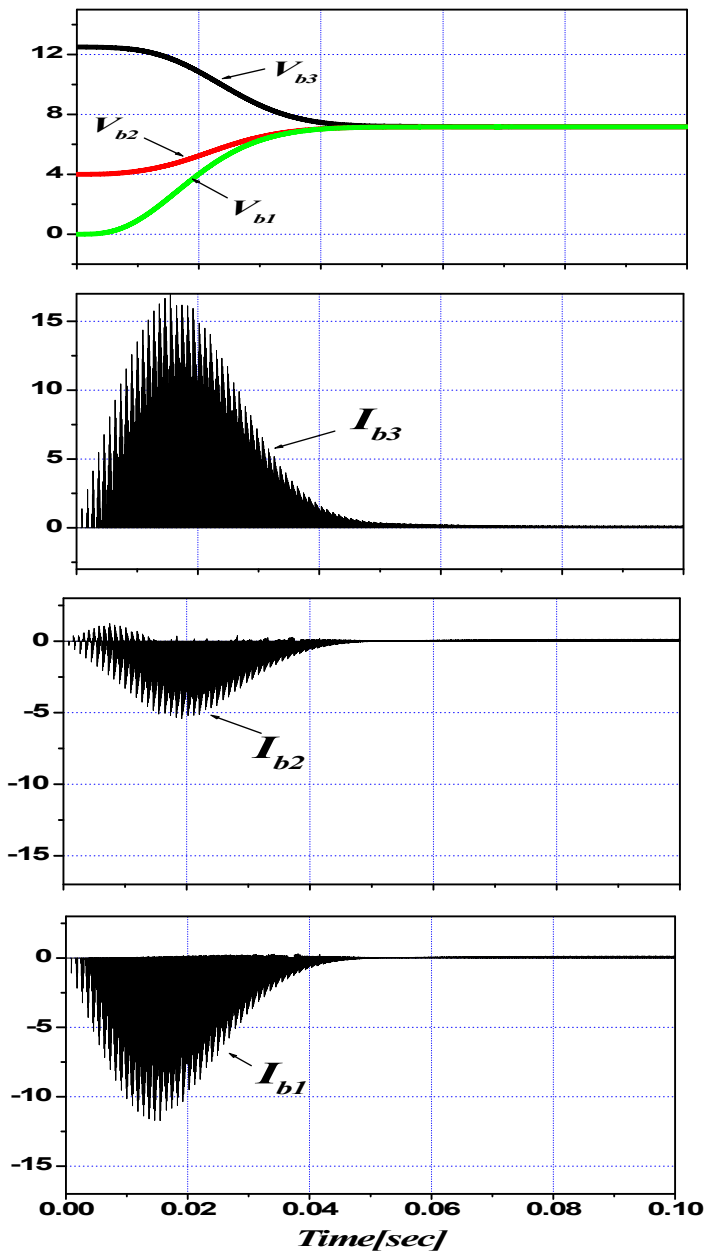

Fig. 8. Result of voltage balancing simulation with the same modules.

this value varies depending on the degree of the soft start of the gate signals. In addition, the value of the balancing voltage was intended to be approximately 7.58 [V], from formula (6), while ignoring the loss. However, it ended up being 7.18 [V] due to the loss.

Fig. 9 shows the results of a simulation to observe the voltage balancing properties with different modules, and it shows 3 types of voltages and the current of each converter. It was assumed that a voltage source $13[\mathrm{~V}]$ was connected to $\mathrm{C} 3$, and that the initial voltages on $\mathrm{C} 1, \mathrm{C} 2$ were set to $0[\mathrm{~V}]$ and $4[\mathrm{~V}]$. As the energy of Condenser $\mathrm{C} 3$ is conveyed to Condensers $\mathrm{C} 2$ and $\mathrm{C} 1$, the voltage of $\mathrm{C} 2$ and $\mathrm{C} 1$ increases and finally it almost converges to the $\mathrm{C} 3$ voltage of $13[\mathrm{~V}]$. The results of this experiment show that by simply constructing a charger in one of the modules connected in series in a floating charge, a charge that maintains the voltage balancing to all of the modules can be obtained. The advantage of this circuit is that it can deliver energy using one electrical power converter regardless of the position of the overcharged or undercharged battery if multiple batteries are connected.

Fig. 10 shows the results of a simulation in the normal state
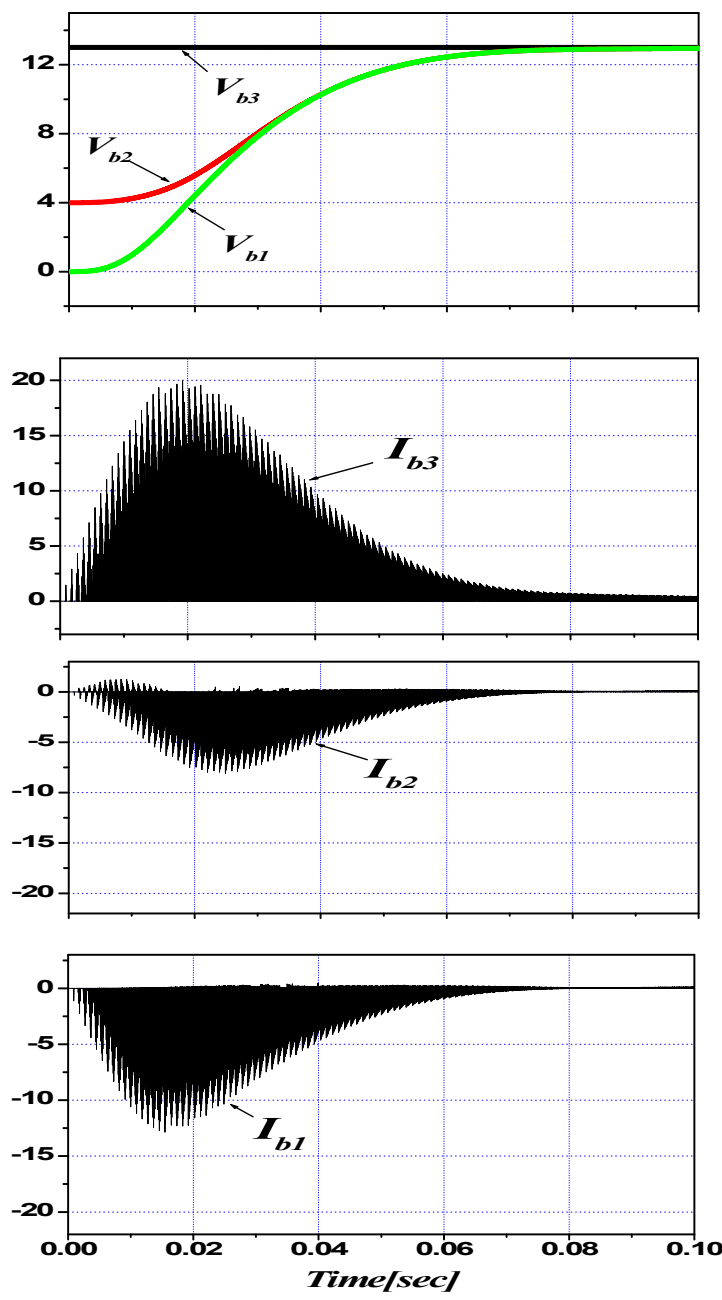

Fig. 9. Result of voltage balancing simulation with different modules.

in which the voltage balancing was completed and shown in Fig. 9. The $\mathrm{C} 1$ voltage and the $\mathrm{C} 2$ voltage are the same, and they are found to be almost the same as the $\mathrm{C} 3$ voltage with a difference of $0.005[\mathrm{~V}]$, while the peak value of the current of the converter is approximately $0.25[\mathrm{~A}]$. The converter's voltage current comes under the reactive current, which is a symmetric wave with a phase difference of almost $180^{\circ}$. The active power is determined by the converter loss. Thus, the proposed circuit finally has some reactive power even after the voltage balancing of the battery. This reactive power is determined by the transformer's exciter inductor. If this value is increased, the reactive power decreases, but the balancing current also decreases, so the time constant for the balancing increases. Therefore, the capacity of the exciter inductor of the transformer should be determined by the rated balancing current.

Fig. 11 shows the voltage balancing properties if a voltage source of $13[\mathrm{~V}]$ is connected to condenser $\mathrm{C} 3$, one of the modules is connected in series, and a $10[\Omega]$ resistive load is applied to condenser C1, a module. As shown in Figure 11, the 

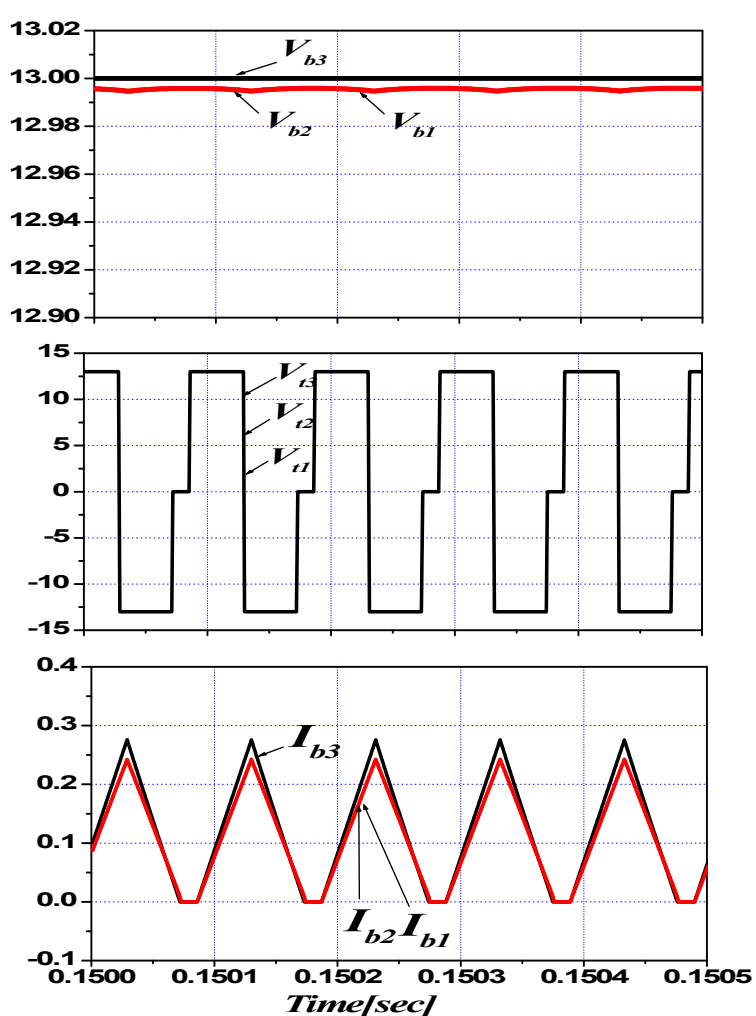

Fig. 10. Operation waveform of the converter after voltage balancing.

voltage and current of converter 3 form a corresponding phase. In addition, the voltage and current of converter 1 show a phase difference of $180^{\circ}$ power conveyed from $\mathrm{C} 3$ to $\mathrm{C} 1$ and the output current of converter 2 is 0 , so the power to $\mathrm{C} 2$ becomes 0 . Furthermore, the voltage of converter 2 is $12.4[\mathrm{~V}]$ while that of converter 1 is 11.9 [V]. This voltage increases in proportion to the output impedance and the load commutation of the converter.

\section{B. Test Results}

Fig. 12 shows the system configuration for the test to verify the validity of the proposed voltage balancing topology. The composition of the test system was the same as that of the simulation, and the AC/DC charge for condenser charging was added. In addition, to generate the gate signals a TMS320F028 DSP was composed.

Fig. 13 shows how the system was built for testing. The system consisted of a triple two-switch forward DC-DC converter circuit equipped with a condenser equivalent to a battery, a single transformer that allows the three DC/DC converters to share the magnetic flux, a wire wound resistor of $10[\Omega]$ for partial loads, a DSP board for PWM control, and an LCD to display the status.

Fig. 14 shows the result of an experiment performed to observe the voltage balancing properties with the same modules. It also shows the gate signals, the voltage of the three condensers and the current of the converters. The initial
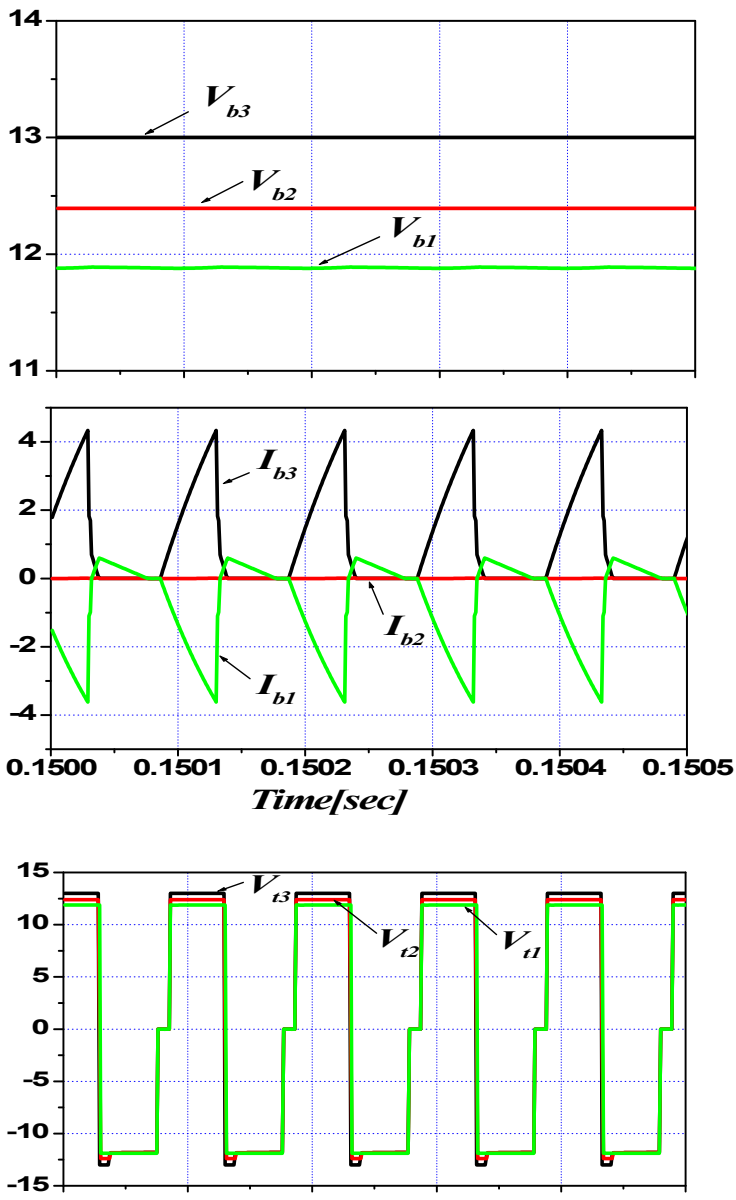

Fig. 11. Voltage balancing operation waveform using local loads.

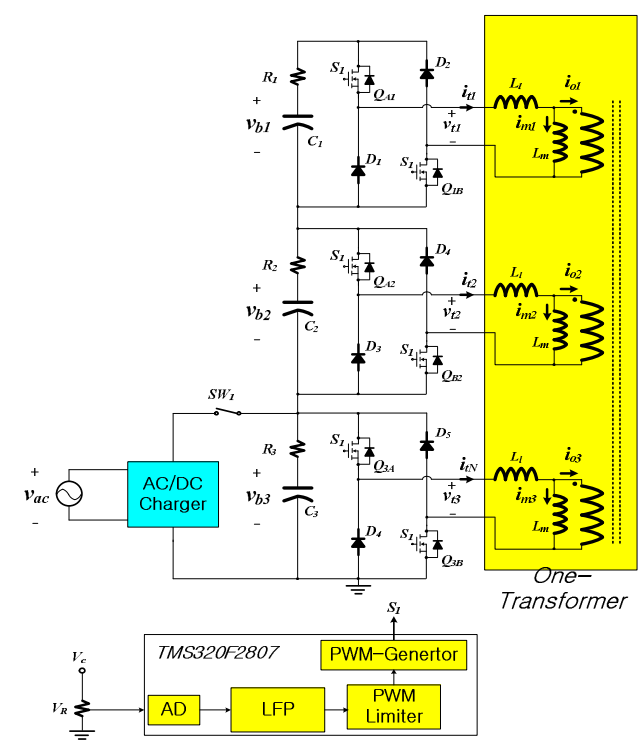

Fig. 12. Proposed voltage balancing test circuit.

voltages of condensers $\mathrm{C} 1, \mathrm{C} 2$ and $\mathrm{C} 3$ were set to $0[\mathrm{~V}], 4$ [V] and $12.5[\mathrm{~V}]$, respectively, as in the simulation. The voltages of condensers $\mathrm{C} 3, \mathrm{C} 2$ and $\mathrm{C} 1$ were finally the same as the simulation. 


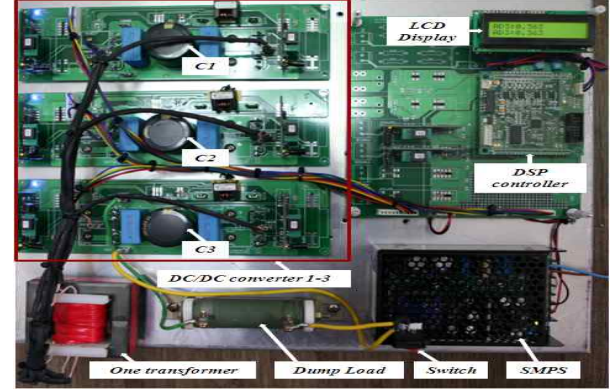

Fig. 13. Building a system for testing.
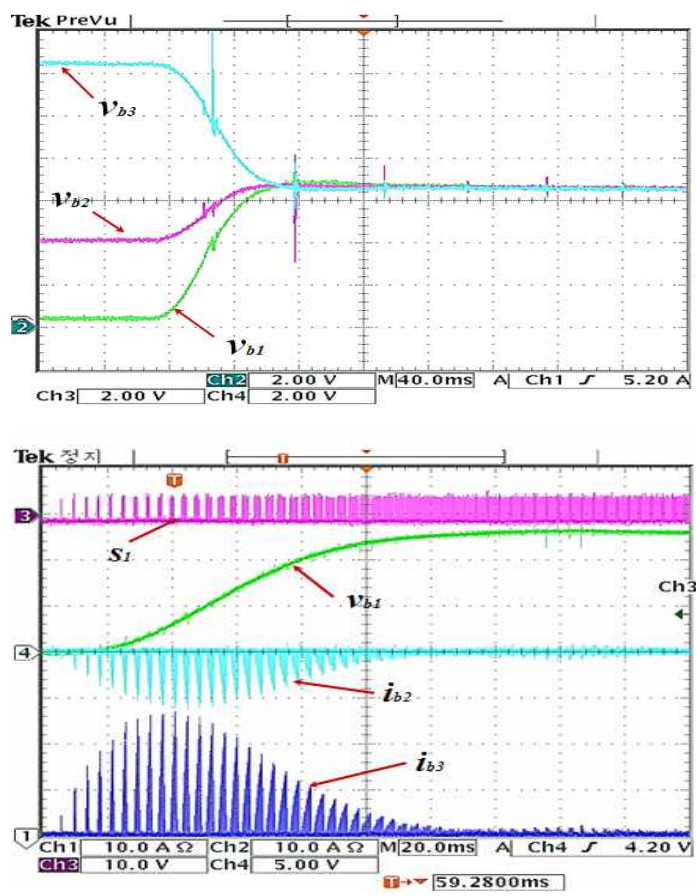

Fig. 14. Result of voltage balancing with the same modules

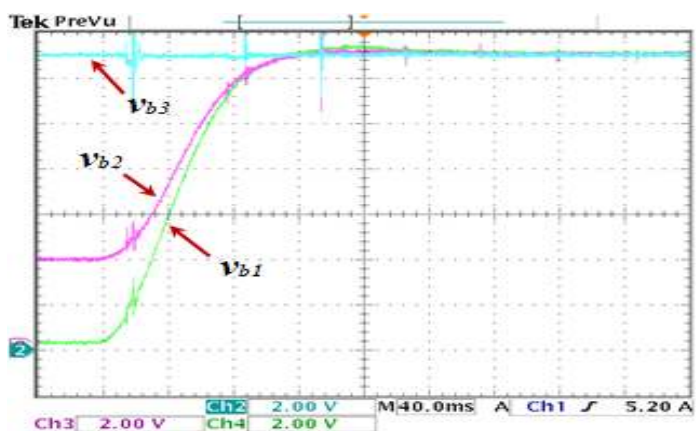

Fig. 15. Result of voltage balancing with different modules

Fig. 15 is the result of a test under the same conditions as Fig. 9, showing 3 types of voltage. As a result of the experiment, the voltage almost converged to $13[\mathrm{~V}]$, with a time constant similarly to the simulation.

Fig. 16 shows the result of a test under the same conditions as Fig. 10. It shows the gate signals, the voltage of converter 1 and the current of converters 1 and 3 . The peak value of the

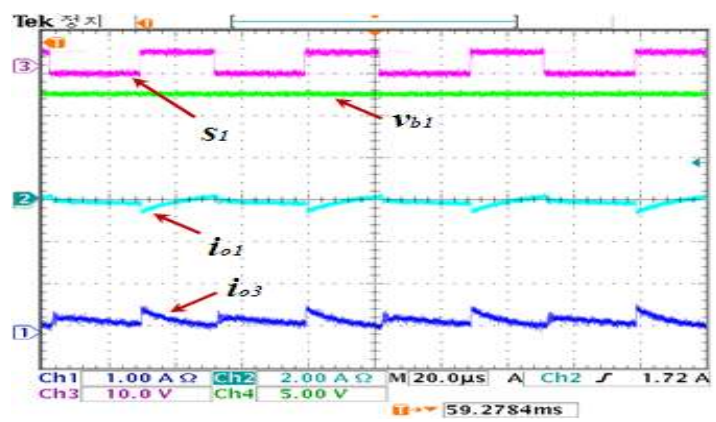

Fig. 16. Operation waveform of the converter after voltage balancing.
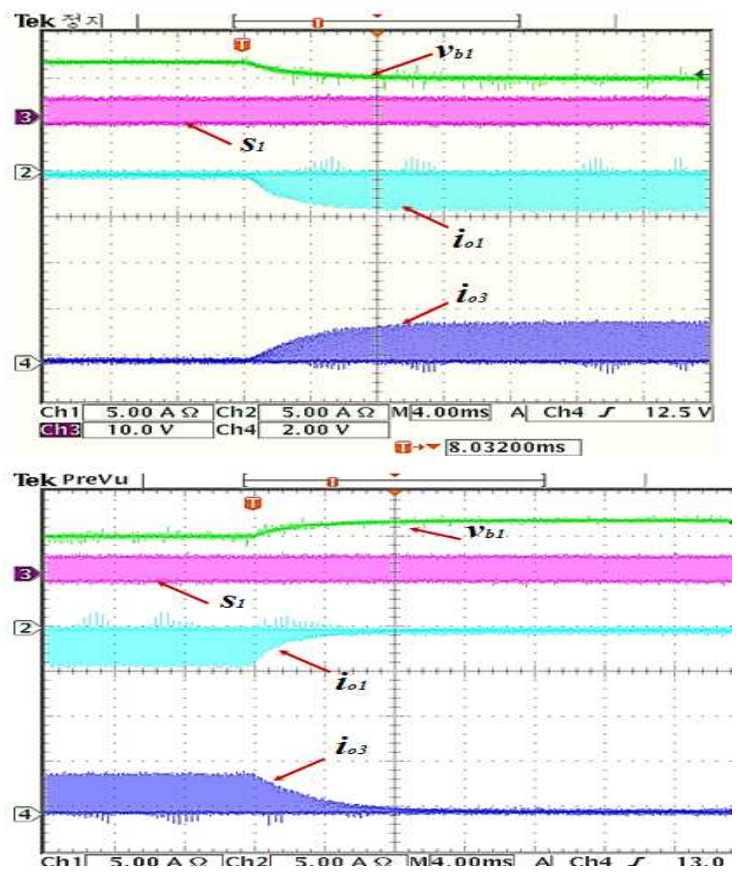

Fig. 17. Result of voltage balancing using local loads.

current of the converter was similar to the simulation. However, due to the loss component not considered in the simulation, the active power was eventually greater than the reactive power in the converters.

Fig. 17(a) shows the characteristic wave pattern when a resistive load of $10[\Omega]$ was made under the same conditions as Figure 11. Fig. 17(b) shows the characteristic wave pattern when the resistive load was broken. As shown in the figure, a normal state is reached approximately $8[\mathrm{~ms}]$ after making and breaking the resistive load. In addition, a voltage fluctuation of 0.8 [V] occurs in the mode conversion. This voltage is in proportion to the output impedance and the load commutation of the converter.

Fig. 18 shows an experimental waveform magnified in a normal state when the local loads in Fig. 17 were used. As shown in the figure, the gate signals and current of converter 3 form a corresponding phase while the gate signals and currents of converter 1 have a phase difference of $180^{\circ}$. Therefore, it can be seen that the power is conveyed from $\mathrm{C} 3$ to $\mathrm{C} 1$. 


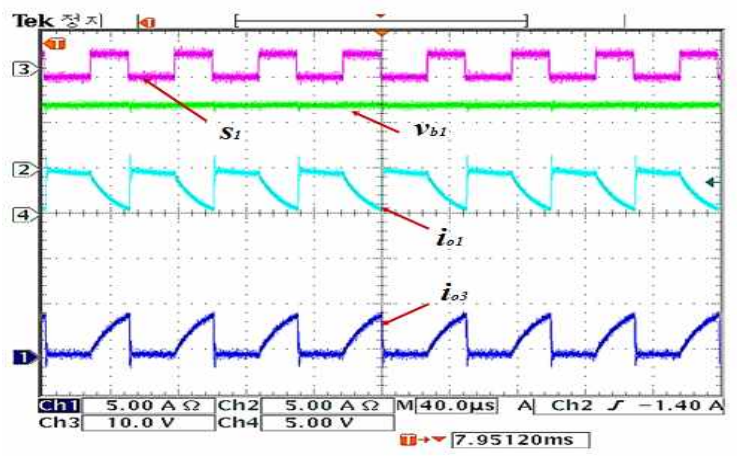

Fig. 18. Characteristic wave patterns in a normal state.

\section{CONCLUSIONS}

The following conclusions were obtained in this study as a result of simulation and testing. In addition, a new magnetic flux sharing type of DC/DC converter topology was proposed to remove the voltage unbalance that can be generated in charging and discharging by the series connection of the battery unit.

With a structure in which an individual DC/DC converter output is connected in a series connected battery to one transformer, voltage balancing was achieved without voltage detection.

For multiple batteries, regardless of the positions of the overcharged or undercharged batteries, energy could be conveyed using one electrical power converter.

It was found that a floating charge using this topology was possible with a battery with a low voltage for cell 1 .

\section{REFERENCES}

[1] W. F. Bently, "Cell balancing considerations for lithium-ion battery systems," in Proc. 12th Annu. Battery Conf. Appl. Adv., pp.223-226.1997.

[2] Y.-S. Lee and M.-W. Cheng, "Intelligent Control battery equalization for series connected lithium-ion battery strings," IEEE Trans. Ind. Electron., Vol. 52, No. 5, pp. 1297-1307, Oct. 2005.

[3] A. M. Imtiaz, F. H. Khan, and H. Kamath, "A Low cost time shared cell balancing technique for future lithium-ion battery storage system featuring regenerative energy distribution," 26th Applied Power Electronics Conference, APEC, pp. 792-799, 2011.

[4] J. Rouillard, C. Comte, R. A. Hagen, O. B. Knudson, and A. Morin, and G. Ross, "Equalizer system and method for series connected energy storing devices," U.S. Patent 5952 815, Sep. 14, 1999.

[5] K. Zhi-Guo, Z. Chun-Bo, L. Ren-Gui, and C. Shu-Kang, "Comparison and Evaluation of Charge Equalization Technique for Series Connected Batteries," Power Electronics Specialists Conference, 2006. PESC '06. 37th IEEE, pp. 1-6, 2006.

[6] A. C. Baughman and M. Ferdowsi, "Double-tiered switched-capacitor battery charge equalization technique,"
IEEE Trans. Ind. Electron., Vol. 55, No. 6, pp. 2277-2285, Jun. 2008

[7] N. H. Kutkut, D. M. Divan, and D. W. Novotony, "Charge equalization for series connected battery strings," IEEE Trans. Ind. Appl., Vol. 31, No. 3, pp. 562-568, May 1995.

[8] C. Pascual and P. T. Krein, "Switched capacitor system for automatic series battery equalization," in Proc. 12th Annu. Appl. Power Electron. Conf. and Exp., pp. 848-854, 1997.

[9] Y. C. Hsieh, C. S. Moo, and W. Y. Ou-Yang, "Bidirectional Charge Equalization Circuit for Series connected Batteries," Power Electronics and Drives Systems, 2005. PEDS 2005. International Conference on , pp. 1578 -1583, 2005.

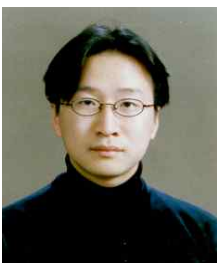

Sung-Geun Song was born in Gwangju, Korea. He received his B.S., M.S., and Ph.D. degrees in Electrical Engineering from Chonnam National University, Gwangju, Korea, in 1998, 2000 and 2007, respectively. From 2001 to 2004, he was a Research Scientist at PROCOM system, Ltd., Korea. From 2004 to 2005, he was a Research Scientist at SEO ELECTRONICS CO., LTD., Korea. Since 2008 he has been with for KETI (Korea Electronics Technology Institute), where he is currently working at the Gwangju Regional Headquarters. His current research interests include power electronics, motor drives, digital signal processing, tractions, and their control systems.

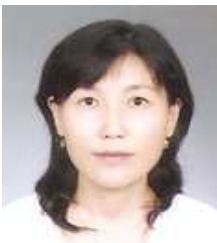

Seong-Mi Park received her B.S., M.S., and $\mathrm{Ph} . \mathrm{D}$. degrees in Electronics and Computer Engineering from Chonnam National University, Gwangju, Korea, in 1986, 2001 and 2011, respectively. From 2004 to 2006, she was a Visiting Professor with the Department of Computer Engineering, Chonnam National University. Since 2013, she has been an Assistant Professor with the Department of Mechatronics Engineering, Korea Lift College, Geochang, Korea. Her current research interests include motor control, mechatronics and micro-machine automation.

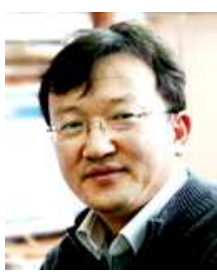

Sung-Jun Park received his B.S., M.S., and $\mathrm{Ph} . \mathrm{D}$. degrees in Electrical Engineering, and a second Ph.D. degree in Mechanical Engineering from Pusan National University, Pusan, Korea, in 1991, 1993, 1996, and 2002, respectively. From 1996 to 2000, he was an Assistant Professor with the Department of Electrical Engineering, Koje College, Koje, Korea. From 2000 to 2003, he was an Assistant Professor with the Department of Electrical Engineering, Tong-Myong College, Pusan, Korea. Since 2003, he has been an Professor with the Department of Electrical Engineering, Chonnam National University, Gwangju, Korea. He is currently a Vice-Professor of Chonnam National University. His current research interests include power electronics, motor control, mechatronics, micro-machine automation, and robotics. Dr. Park is a Member of the Korean Institute of Electrical Engineers and the Korean Institute of Power Electronics. 